\title{
Application of Continuous Animation Production Technology in Gymnastics Multimedia Teaching
}

\author{
http://dx.doi.org/10.3991/ijet.v11i09.6123 \\ Changhui Xia \\ Hubei University of Arts and Science, Xiangyang, China
}

\begin{abstract}
- to facilitate improvement of education and teaching modernization level in China, and promote maturity and development of multimedia teaching technology, this paper established continuous animation multimedia teaching system based on continuous animation production technology. Meanwhile, this paper took gymnastics teaching of 2015 gymnastics class in Hubei University of Arts and Science in Hubei province of China as the objects of experiment and explored teaching effect of this multimedia teaching system combined with continuous animation production technology. The results show that this multimedia teaching system combined with continuous animation production technology can significantly improve students' theoretical and practical examination scores. Based on case study of application of continuous animation and multimedia technology in gymnastics teaching, this paper aims to make certain contributions to promotion and development of multimedia teaching technology.
\end{abstract}

Index Terms-continuous animation, gymnastics teaching, multimedia

\section{INTRODUCTION}

Computer animation refers to a series of scenery pictures which are generated by graphics and image processing technology with the help of programming or animation production software. Current frame is partlymodified previous frame. Computer animation generates object moving effect through continuously playing still images [1]. This study aims to the influence of computer animation technology on students' learning in the 'Solar System and Beyond' unit which is taught as a part of the Science and Technology course of Grade 7 in primary education. The results indicate that computer animation technology has better effects than traditional teaching methods in the aspect of enhancing students' achievements. Roth et al. [3] proposed to combine animation technology with multimedia technology in biological teaching. With the development of modern science and technology, animation technology gains continuous improvement. They propose integration of free vibration theory and computer graphical technology to display mode shapes of a three-dimensional framework. In this way, one can see real-time animation of the structural mode shapes on the computer screen. Wang [4] put forward 3D animation technology on the basis of animation technology and believed that implementation and influence of different motion blur effects are different in accordance with technical differences between 3D animation of the various stages in the process. Besides, he focused on analysis of different stages of animation blur effect technology in animation and its influence differences.
Physical education (PE) is one of education emphases in modern education. PE can help juveniles improve their physical quality and psychological quality, so it plays a crucial role for healthy growth of juveniles [5]. In traditional education and teaching mode, the teacher teaches PE theory and action modeling uniformly, and students learn and practice uniformly. For traditional PE teaching mode, since teachers have different teaching level and there is short of human resource, students cannot get personalized, comprehensive and visualized guidance. Thus, students' motions are not standard, and the expected teaching effect cannot be reached. Moreover, current college students have prominent learning individuality, which proposes a challenge to college PE objectively in the new period. Traditional teaching mode in which the teacher sets an example and gives explanations in person and students follow and imitate the teacher has shown the contradiction with students' learning individuality. Meanwhile, it cannot adapt development situation of multimedia era. The direct consequence brought by outdated teaching mode is that teaching effect is dissatisfactory. Besides, the phenomena of skipping PE course and giving up PE course are very common [6].

With current education demand and restriction on course duration, traditional education method cannot keep pace with rapid development of digital era. The application of animation technology in teaching can enhance teaching effect [7]. Liu Yong [8] utilized powerful function of FrontPage and combined text, image, voice and animation etc. to proposes an internet-based design scheme for basketball CAI courseware. The scheme brought vivid teaching environment in basketball teaching class, obtained good teaching effect and increased students' scores. When teaching animation was produced previously, continuous animation was usually generated through adjusting vertex animation with plug-in. It is difficult for teachers who do not major in computer to master such production method. Or, it is necessary to pay for corresponding FLASH to replace continuous animation. In addition, such FLASH animation resource is limited, and cannot be flexibly produced and displayed according to course content [9]. In view of the above situations, an improvement method is innovatively proposed in this experiment in order to overcome the above defects in existing technology.

\section{TeChNicAl CONTENT OF CONTINUOUS ANIMATION}

\section{A. Technical background of continuous animation}

In animation production process, if several pictures are played in a continuous and repeated way, the effect of animation continuity can be reached so that the pictures 
are more vivid, and can be played more fluently. Continuous animation technology has direct influence on animation effect, so continuous animation technology plays a crucial role in animation production process. The application of continuous animation technology can better improve video fluency, enhance students' watching effect and give people more real viewing experience.

In the past, continuous animation was produced by adjusting vertex animation or sequence frame animation with plug-in or assistant software so as to reach the purpose of continuous animation playing. For vertex animation, manual frame extraction and recovery technology are used to make animation continuous. Such manual operation method is heavy and complicated, with low efficiency. For sequence frame animation, semitransparent mixing technology is applied to make animation continuous. Since original animation is destroyed in the mixing process, animation watching effect is often poor.

The above two traditional continuous animation production methods destroy original animation to different degrees, so the expected animation effect cannot be gained. Thus, this paper introduces a new method to produce continuous animation, without the damage to original animation. Such new method is applied in multimedia teaching system to improve the production level of multimedia teaching system.

\section{B. Technical content of continuous animation}

(1) Firstly, open the pictures of the same size; the size of pictures should be consistent in order not to make pictures malpositioned; meanwhile, the size of pictures can be modified after they are opened. See figure 1 .

(2) Drag the pictures in a folder, as shown in figure 2.

(3) Double click unlocking background image and copy one layer at $\mathrm{Ctrl}+\mathrm{J}$, as shown in figure 3 .

(4) Establish three reference lines and view reference line; based on original width of pictures, 300 pixel is set firstly; the references lines are 600 pixel and 900 pixel. as shown in figure 4.

(5) Compare pictures with the reference liens, respectively.

(6) Merge all visible picture layers by pressing $\mathrm{Ctrl}+\mathrm{E}$.

(7) Turn to cutting tool (shortcut key D), cut and arrange according to the contents needed; the size after cutting is original size of picture: $300 \times 210$ pixel, as shown in figure 4.

(8) Turn to animation editing.

(9) Open window - animation panel.

(11) Copy current frame

(12) Turn to moving tool, and press shift key to drag the picture layer. For example, "dragging process" is shown; finally, drag to the last picture to make it coincide with the first picture.

(13) Add transition frame. Frame setting: each picture moves 6 frames, and 4 pictures in total need to move, i.e. $4 \times 6=24$ frames; because the last frame and the initial frame repeat, one frame is subtracted, i.e. 23 frames.

(14) Finally, properly add the time of that frame when each picture is displayed completely.

(15) Export previous high-quality picture setting

(16) The file is saved to GIF format.

\section{Continuous animation multimedia teaching system}

In continuous animation multimedia teaching system, continuous animation technology is applied in multimedia teaching to reach the purpose of improving video courseware quality. The implementation process of continuous animation multimedia teaching system is as follows: (1) designers collect continuous video production materials through shooting, network retrieval or oncampus database retrieval, such as gymnastic movement decomposition picture and teaching voice; (2) preliminarily process and screen the materials collected; (3) apply continuous animation technology to process the materials so as to form continuous animation; (4) upload continuous animation to continuous animation multimedia teaching system for teachers and students to watch online or download.

Figure 5 shows computer interface of continuous animation multimedia teaching system. Continuous animation multimedia teaching system offers four main functions: video playing, material uploading, video downloading, discussion and communication. When this system is applied for learning, students may watch video online through video playing function, or store the video needed through video downloading function for viewing it anytime. In addition, continuous animation multimedia teaching system also provides material uploading function. Students may upload complete video or continuous pictures and voice through material uploading module, and apply this system for synthesis of continuous animation. In discussion and communication module, students may communicate with the teacher in an all-round way, including knowledge about gymnastics course and video problem feedbacks. Through this module, this system can be improved and enhanced.

It can be seen from figure 3 that in video playing module, students can freely select teaching videos of different teachers so as to meet their preference to teachers and make the system better match with user demand. Moreover, students may produce exclusive video with this system and upload it to video database for other users to watch. Meanwhile, other teachers and students can help correct the mistakes.

\section{EXPERIMENT AND ANALYSIS}

To verify the application effect of continuous animation multimedia teaching system in gymnastics teaching, and facilitate the application of multimedia technology in teaching practice, this paper took the students of 2015 gymnastics class in Hubei University of Arts and Science in Hubei province of China for example and verified the effect of this system through comparing teaching effects of experimental group and control group.

\section{A. Objects of experiment}

68 students were chosen at random from 2015 gymnastics class in Hubei University of Arts and Science in Hubei province of China, including 39 male students and 29 female students. The objects of experiment were divided into two groups at random, and there were 34 students in each group. Continuous video multimedia teaching system was applied in gymnastics course teaching for the experimental group, while conventional teaching method was adopted for control group. The teaching duration of each group was 2 weeks. $100 \mathrm{~min}$ gymnastics theory teaching 
Application of Continuous Animation Production TeChNOlogy in GyMnastics Multimedia TEACHing

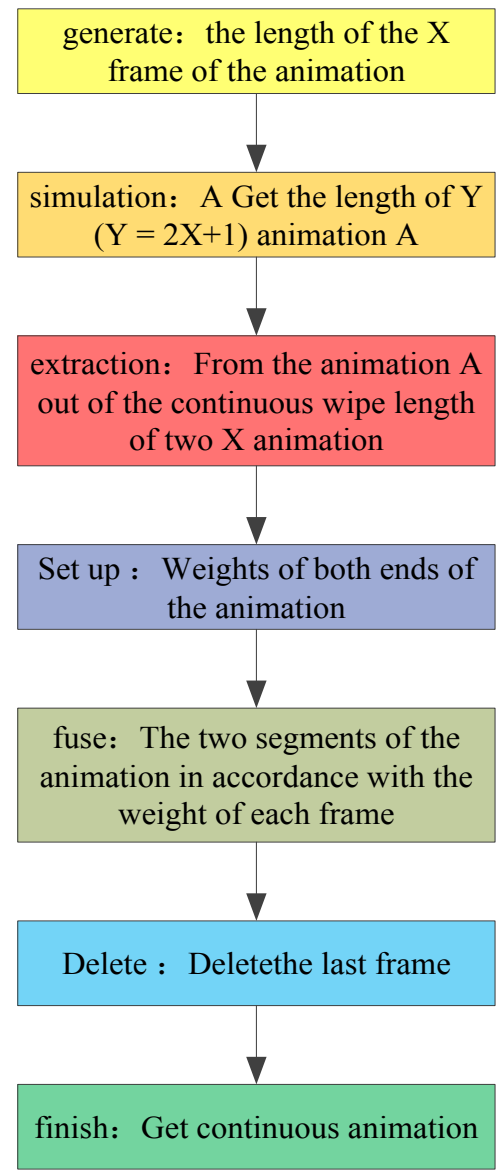

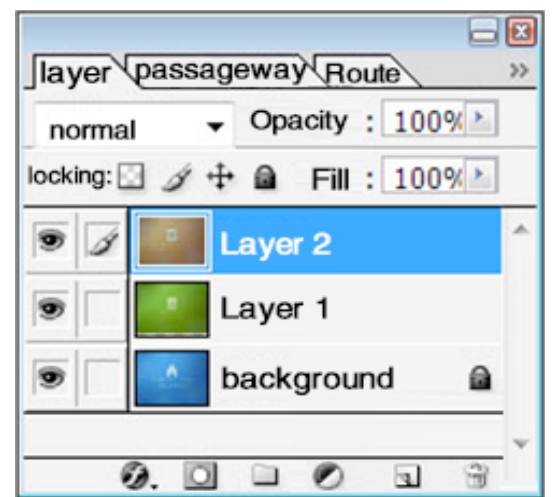

Figure 2. Drag the pictures in a folder

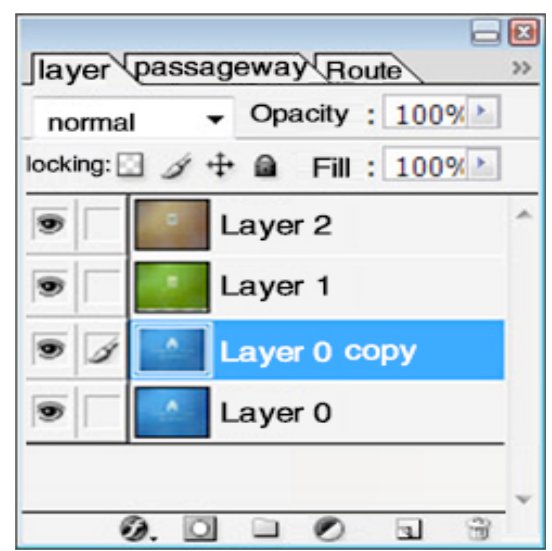

Figure 3. Double click unlocking background image

Figure 1. Structure of continuous animation

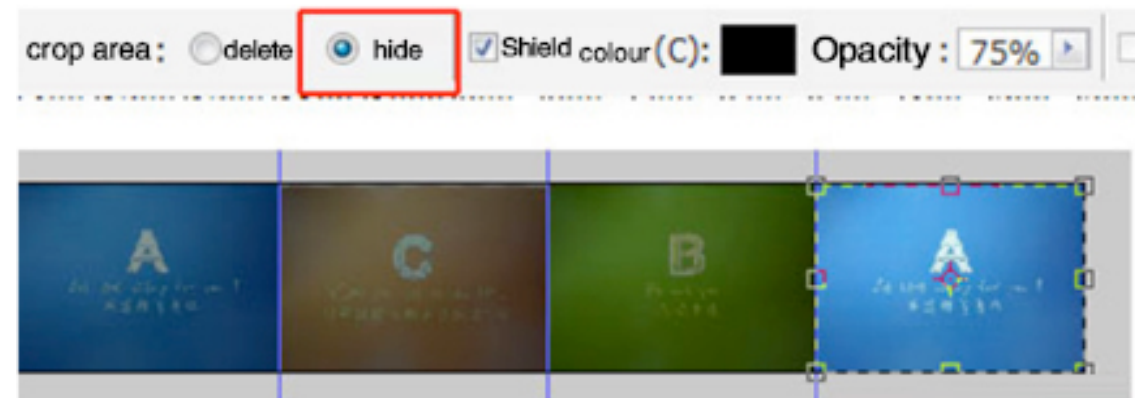

Figure 4. The size of picture after cutting

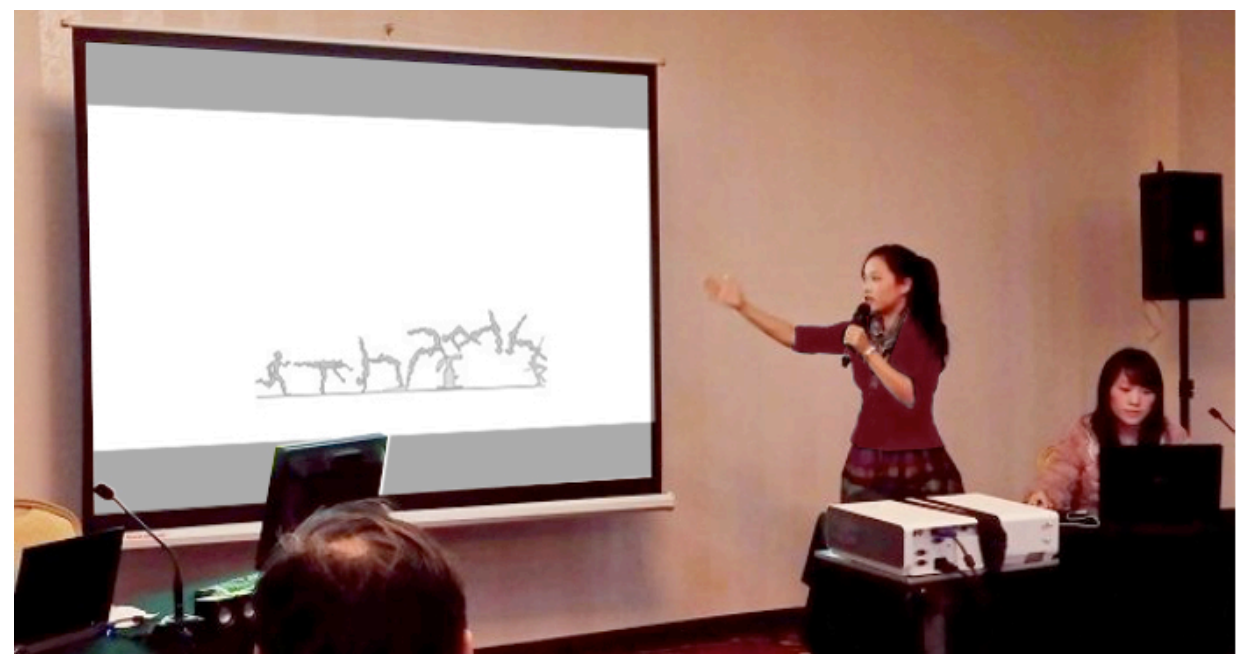

Figure 5. Video interface of continuous animation multimedia teaching system 
was conducted every day according to teaching program. The differences of two groups in gender, age and score had no statistical significance $(\mathrm{P}>0)$. Both teachers of two group were deputy directors of gymnastics teaching and research office, so they owned rich theory and practice teaching experience.

\section{B. Evaluation mode}

After two-week gymnastics teaching ended, examination and questionnaire survey were carried out for the students in two groups so as to fully know teaching effect and students' learning experience. There were three evaluation modes:

(1) Theory examination. After teaching ended, theory examination was conducted for students according to teaching content, and the examination results were recorded and analyzed.

(2) Practice examination. After teaching ended, professional teachers were organized to examine students' corresponding gymnastic movements. Students' practice examination results were recorded in the form of average score.

(3) Questionnaire survey. Questionnaire survey was conducted for 34 students in the experimental group so as to fully know students' feeling for continuous animation multimedia teaching system.

\section{Results}

The comparison of examination scores of two groups is shown in table I. The evaluation of students in experimental group on continuous video multimedia teaching system is shown in table II, Suggestions of experimental group on improvement of continuous video multimedia is shown in table III.

As computer information technology develops continuously, the space for combining multimedia and education becomes increasingly broad, which facilitates the development of information-based education. At present, the researches on combination of multimedia and gymnastics teaching in college PE are few. It can be seen from Table I that, the average score of theory examination and practice examination of students who were taught with continuous animation multimedia teaching system is significantly higher than that of students who were taught with conventional teaching method. The average score of theory examination of students in experimental group is 88.29 , much higher than 80.03 of control group. The average score of practice examination of students in experimental group is 86.33 , while the average score of practice examination of students in experimental group is only 77.28. Seeing from the examination scores, continuous video multimedia teaching system significantly improves students' theory and practice learning efficiency, and promotes students to improve gymnastics performance rapidly. Therefore, continuous video multimedia teaching system has satisfactory effect in gymnastics teaching. Continuous animation multimedia teaching system has popularization and promotion value.

Table II shows questionnaire survey of students in experimental group on evaluation of continuous animation multimedia teaching system. It can be seen from Table II that $91.18 \%$ of students consider that the overall effect of continuous animation multimedia teaching system is significant, and only $8.82 \%$ of students think the overall effect of this system is general. This proves that students

TABLE I.

COMPARISON OF EXAMINATION SCORES OF TWO GROUPS SCORE

\begin{tabular}{|l|c|c|c|}
\hline \multicolumn{1}{|c|}{ Group } & Number & Theory examination score & Practice examination score \\
\hline Experimental group & 34 & $88.29 \pm 2.98$ & $86.33 \pm 1.56$ \\
\hline Control group & 34 & $80.03 \pm 3.10$ & $77.28 \pm 2.65$ \\
\hline $\mathrm{t}$ & & 14.69 & 13.66 \\
\hline $\mathrm{P}$ & & $<0.01$ & $<0.01$ \\
\hline
\end{tabular}

TABLE II.

EVALUATION OF STUDENTS IN EXPERIMENTAL GROUP ON CONTINUOUS VIDEO MULTIMEDIA TEACHING SYSTEM (N=4)

\begin{tabular}{|l|c|c|c|}
\hline \multicolumn{1}{|c|}{ Item } & Significant effect significance & General effect & Poor effect \\
\hline Video fluency & $30(88.24 \%)$ & $4(11.76 \%)$ & $0(0 \%)$ \\
\hline Improve learning interest & $32(94.12 \%)$ & $2(5.88 \%)$ & $0(0 \%)$ \\
\hline Improve learning efficiency & $27(79.41 \%)$ & $6(17.65 \%)$ & $1(2.94 \%)$ \\
\hline Beneficial to knowledge application and understanding & $28(82.35 \%)$ & $5(14.71 \%)$ & $1(2.94 \%)$ \\
\hline Improve classroom interestingness & $33(97.06 \%)$ & $1(2.94 \%)$ & $0(0 \%)$ \\
\hline Entire effect & $31(91.18 \%)$ & $3(8.82 \%)$ & $0(0 \%)$ \\
\hline
\end{tabular}

TABLE III

SUGGESTIONS OF EXPERIMENTAL GROUP ON IMPROVEMENT OF CONTINUOUS VIDEO MULTIMEDIA TEACHING SYSTEM

\begin{tabular}{|l|c|c|}
\hline \multicolumn{1}{|c|}{ Item } & Yes & No \\
\hline The number of videos needs increase & 20 & 14 \\
\hline The number of teaching subjects needs increase & 30 & 4 \\
\hline Video fluency needs enhancing & 5 & 29 \\
\hline System interface setting needs enhancing & 18 & 16 \\
\hline System functions need increase & 19 & 15 \\
\hline
\end{tabular}


affirm the effect of this system, so it is deserves application and promotion. During evaluation of this system, students highly approve video fluency. Most students believe that animation video playing effect is good, which is one of major highlights of this system. The system promotes improvement of teaching quality through boosting fluency and authenticity of multimedia teaching system. According to Table II, continuous animation multimedia teaching system significantly improves classroom interestingness as well as students' gymnastics learning interest and learning efficiency. Video teaching enhances students' understanding of gymnastic movement, better guides students' practice and facilitates students' movement standardization and theoretical knowledge proficiency.

It can be seen from Table III that the major problem of continuous animation multimedia teaching system is that the teaching subjects need increase. Since this system is in the testing stage, only gymnastics course study is provided. As the system is gradually applied and improved, the number of subjects will certainly increase. The most satisfactory point of continuous video multimedia teaching system is its video playing fluency. Most students in experimental group consider that this system has very high video fluency, which cannot be separated from advanced continuous video technology. Furthermore, the students in experimental group also think the number of teaching videos needs to further increase, and interface production needs to improve. These problems will be mainly considered in future system improvement.

\section{CONCLUSION}

This paper introduced continuous animation technology in detail, constructed continuous video multimedia teaching system, and presented system functions and interface composition. This paper took the students of 2015 gymnastics class in Hubei University of Arts and Science as the objects of experiment and explored the application effect of continuous video multimedia teaching system in gymnastics teaching. (1) Continuous video multimedia teaching system is bale to significantly promote students to strengthen theory and practice ability, enhance students' learning interest and learning efficiency, and facilitate students to master and apply theoretical knowledge. (2) Continuous animation multimedia teaching technology is characterized by that visuality, scienti- ficity, high efficiency and operation easiness. Diversification of animation courseware and 3D optimal combination make teaching effect in the best state. Therefore, continuous animation multimedia teaching system greatly promotes gymnastics teaching. Hence, it is suitable for application and promotion.

\section{REFERENCES}

[1] Smith D., Mclaughlin T., Brown I., "3-D Computer Animation vs. Live-Action Video: Differences in Viewers' Response to Instructional Vignettes," Contemporary Issues in Technology \& Teacher Education, vol. 12, no. 1, pp. 41-54, March 2012.

[2] Aksoy G., "Effect of Computer Animation Technique on Students' Comprehension of the," Mevlana International Journal of Education, vol. 3 no. 1, pp. 40-46, April 2013. http://dx.doi.org/10.13054/mije.13.02.3.1

[3] Roth W.J., Shvets O.V., Shamzhy M., et al., "Postsynthesis Transformation of Three-Dimensional Framework into a Lamellar Zeolite with Modifiable Architecture," Journal of the American Chemical Society, vol. 133, no. 16, pp. 6130-6133, April 2011. http://dx.doi.org/10.1021/ja200741r

[4] Wang S., "Motions Blur Effects in the Process of ThreeDimensional Animation Technology Research," Applied Mechanics \& Materials, vol. 687-691, pp. 1170-1173, November 2014.

[5] Yan B., "Physical Education Based on PE Physical Education Technology," Sports World (Scholarly), no. 9, pp. 74-75, September 2010. http://dx.doi.org/10.4028/www.scientific.net/AMM. 687-691.1170

[6] Cui J.G., Wang Z.S., "Enlightenment of Multimedia Network Platform on College PE," News Front, no. 12, pp. 50-51, June 2015.

[7] Musa S., Ziatdinov R., Sozcu O.F., et al., "Developing Educational Computer Animation Based on Human Personality Types," Social Science Electronic Publishing, vol. 11, no. 1, pp. 52-71, March 2015.

[8] Liu Y., Zhong P., Liu W., "The Design of Basketball CAI Courseware Based on Internet Technology," Sichuan Sports Science, vol. 21, no. 1, pp. 63-64, March 2002.

[9] Huang R., "Digital PE Teaching Platform Based on ADDIE Model," Sports Research and Education, vol. 28, no. 5, pp. 69-72, October 2013.

\section{AUTHORS}

Changhui Xia is a Lecturer of PE College, Hubei University of Arts and Science, Xiangyang, 441053, China. His research interests include physical education and Multimedia Teaching. (shangwei12@yeah.net)

Submitted 07 August 2016. Published as resubmitted by the authors 16 September 2016. 